\title{
Bronchoscopy and fine needle aspiration cytology aided diagnosis of suspected lung malignancy- A prospective observational study
}

\author{
Pant S', Shrestha SK², Sharma L', Mahaseth $\mathrm{R}^{3}$, Neopane $\mathrm{A}^{4}$ \\ ${ }^{1}$ Subash Pant, Lecturer; ${ }^{2}$ Sanjeet Krishna Shrestha, Assistant Professor,'Lucky Sharma, Lecturer; ${ }^{3}$ Rinky Mahaseth, Medical \\ Officer; ${ }^{4}$ Arpana Neopane, Professor and Head of Department, Department of Internal Medicine, Kathmandu Medical \\ College Teaching Hospital, Kathmandu, Nepal.
}

\begin{abstract}
Background: Flexible bronchoscopy is the main modality of diagnosing lung malignancy as per the location of lesion in our setup. Accurate diagnosis and categorization into various types is vital for its prognostic and management point of view.

Objectives: The study was conducted to find out yield of bronchoscopy and FNAC in suspected lung lesion and to know the various subtypes of bronchogenic carcinoma.

Methodology: The study was conducted in Kathmandu Medical College Teaching Hospital from December 2016 to May 2018. This was a prospective observational study conducted in 90 radiological suspected lung lesions. Radiological, bronchoscopy, histopathological and cytopathological findings were analyzed and evaluated. Data were recorded on a pre-designed proforma and entered into Statistical Package for the Social Sciences version 20.

Results: Among 90 suspected lung lesions who underwent contrast enhanced computed tomography, chest mass lesion was seen in $57(63.3 \%)$ subjects, nodular in $8(8.9 \%)$, consolidation in $7(7.8 \%)$, fibrosis in $7(7.8 \%)$, collapse in $6(6.7 \%)$ and pleural effusion in $3(3.3 \%)$. The most common malignancy was squamous cell carcinoma (53.48\%). Lung malignancy was more common among endobronchial growth. The tendency of lesion to be malignant however tended to be significant at right upper lobe $(p=0.02)$. When the suspected lesion was mass, the occurrence of malignancy was significantly higher $(p<0.05)$.

Conclusion: The diagnostic yield increases with presence of right upper lesion with endobronchial growth. When the lung lesion presents as mass, the yield of having malignancy is also higher.
\end{abstract}

Key words: Bronchoscopy; Histopathology; Lung malignancy

DOI: https://doi.org/10.3126/jkmc.v7i4.23320

\section{INTRODUCTION}

Tucan unc ung malignancy is the leading cause of cancer and cancer related death worldwide. The incidence and mortality due to lung malignancy is the most common among men, and among women, it has the third highest incidence, and is second after breast malignancy in mortality ${ }^{1}$. In the United States, lung cancer is the second most common cancer, after prostate cancer in men and breast cancer in women, but the most common cause

Address for correspondence

Dr. Subash Pant

Lecturer, Department of Internal Medicine,

Kathmandu Medical College and Teaching Hospital

Sinamangal, Kathmandu.

E-mail: subashpant26@gmail.com of cancer deaths. The American Cancer Society projects that 234,030 cancers of the lung and bronchus will be diagnosed in the United States in 2018, with 154,050 deaths ${ }^{2}$. According to the Global Cancer Observatory (GLOBOCAN) 2012 report, the estimated incidence of lung cancer in India was 70,275 in all ages and both sexes $^{3}$.

In Nepal, as per data published in April 2011, lung malignancy death number was 3100 , that was $2.09 \%$ of total mortality. Lung cancer was ranked $15^{\text {th }}$ among leading cause of death in Nepal. The death rate as per age in the study was 19.36 per 100,000 of population. This gave the Nepal with ranking of 68 among lung cancer related deaths worldwide ${ }^{4}$. 
Tissue sampling is required to confirm diagnosis in all the patients with suspected lung cancer. Sampling of the lesion can be made by biopsy through flexible bronchoscopy or by fine needle aspiration (FNA) of suspected peripheral lymph node or mass where the scope is difficult to assess. Flexible bronchoscopy is still the main procedure in collecting the samples for diagnosing the lung malignancy as per the location of lesion.

The study was conducted to find out the various types of bronchogenic carcinoma and its radiological correlation. Bronchoscopy and Fine Needle Aspiration Cytology (FNAC) were the two different modalities that helped in diagnosing the suspected lesions.

\section{METHODOLOGY}

This is a prospective cross sectional study. The study was conducted in Kathmandu Medical College Teaching Hospital from December 2016 to May 2018 over a period of 18 months. Both inpatients and outpatients were included. Written as well as verbal consent were taken from the participants. Total 90 cases with chest x-ray demonstrating a new or enlarging focal lesion, a pleural effusion, pleural nodularity, enlarged hilar or paratracheal nodes, endobronchial lesion, postobstructive pneumonia or atelectasis were enrolled into study. A detailed history regarding symptoms of cough, hemoptysis, weight loss, shortness of breath and smoking history were taken. Both written and informed consent were taken from the patient.

Patient underwent routine investigation including serology and blood clotting factors. Patient then underwent intravenous contrast induced Computed Tomography (CT) chest with lung window, mediastinal window and bone window. Then these patients proceed for routine bronchoscopy. In bronchoscopy, analysis of bronchial biopsies, bronchial brushings and bronchoalveolar lavage were done. Patient with difficult lesion to explore by bronchoscopy proceeded for $\mathrm{CT}$ or Ultra sonogram (USG) guided FNAC. There were cases where sample were taken from supraclavicular Lymph node via FNAC as well. All the samples obtained were then sent for analysis in pathology laboratory. The histopathological and cytopathological reports were reviewed and later compared with that of Contrast Enhanced Computed Tomography (CECT) chest reports. Cytopathological methods included Broncho-Alveolar Lavage (BAL), Bronchial Brush (BB) and FNAC.

CECT chest findings were classified as normal or abnormal: Mass Lesion, Nodular, Consolidation, Fibrosis, collapse and pleural effusion. Bronchoscopy findings were classified as normal or abnormal: Endobronchial growth, endobronchial narrowing, inflammation, extraluminal compression, endobronchial obstruction, endobronchial secretion, haemorrhage and anatomical distortion. Histological and cytopathological reports were labeled as positive and negative for malignancy. Positive reports for malignancy were classified as follows: squamous cell carcinoma, small cell carcinoma, adenocarcinoma and metastatic undifferentiated.

Data were recorded on a pre-designed proforma and entered into International Business Machines Corporation-Statistical Package for the Social Sciences (IBM-SPSS) version 20. Baseline characteristics of patients were evaluated using descriptive statistics. Categorical variables were expressed in frequency (\%). Quantitative variables were assessed for approximate normality. Variables following approximately normal distribution were summarized by mean \pm SD. All data were evaluated using IBM-SPSS version 20. Statistical significance were set with $p$ value $<0.05$ with Confidence Interval of $95 \%$. Chi-square and Fischer exact test were used for categorical data.

\section{RESULTS}

The mean age of the study population was $64.49 \pm 10.9$ years. The youngest patient to have diagnosed lung cancer was 42 years old and the oldest patient was 82 years old. Half of the study population were male. The occurrence of malignancy as per either sex was not significant $(p-0.49)$.

Among the 90 suspected lung lesions, mass lesion was seen in $57(63.3 \%)$ subjects, nodular in $8(8.9 \%)$, consolidation in $7(7.8 \%)$, fibrosis in $7(7.8 \%)$, collapse in 6 (6.7\%) and pleural effusion in 3 (3.3\%). Among 90 patients, bronchoscopy was done in 84 patients. Remaining 6 with difficult lesion underwent CECT mediated FNAC or direct FNAC of peripheral lymph node. Among bronchoscopy findings, the most common finding was endobronchial growth in 34 (40.47\%), endobronchial narrowing in 16 (19.04\%), extraluminal compression in $6(7.14 \%)$ and normal in $6(7.14 \%)$.

Out of total 90 suspected lesions, malignancy was positive in $43(47.8 \%)$ cases. Histopathological examination (HPE) and cytopathological reports were both incorporated for this purpose. Remaining 43 $(47.8 \%)$ cases had negative report for malignancy and 4 (4.4\%) cases had tuberculosis. The most common malignancy was squamous cell carcinoma (53.48\%). Out of total 43 positive cases, squamous cell carcinoma 
was seen in 23 cases. The positive cytopathological and histological examinations reports are enlisted in table2.

Out of 60 cases where HPE were done, 30 (50\%) had positive sample reports (either malignancy or tuberculosis) in our setup (Table 3). The commonest symptoms patient presented among lung cancer were cough, hemoptysis and weight loss (Table 4).

Regarding smoking, which was always considered a risk factor for lung malignancy ${ }^{1}$, the correlation was not so significant in the study ( $p-0.25)$. Clubbing was also only present in 10 (23.25\%) malignancy positive cases which also had no significant correlation. $(p=0.31)$.

As per the side of lesion, $56(62.2 \%)$ had right sided lesion and 34 (37.8\%) had left sided lesion. Among lobe, the most common site was the right upper lobe (31.1\%) followed by left upper lobe (25.6\%) and right middle lobe (17.8\%) respectively. The tendency of lesion to be malignant however tends to be significant at right upper lobe $(p=0.02)$.

The chest x-ray or CECT chest with suspected lesion who had mass, the occurrence of malignancy were significantly higher $(p<0.05)$. This correlation was however not so significant when the lesion were other than mass.

Regarding the bronchoscopy findings, $40.47 \%$ of the patient had endobronchial growth and $19.04 \%$ had endobronchial narrowing. The EBG had significant correlation in occurrence of malignancy $(p=0.02)$. However, the endobronchial narrowing had no significant correlation with regards to this $(p=0.35)$
Table 2: Various subtypes of lung malignancy

\begin{tabular}{lr}
\hline Tumor type (Malignancy)-43 & Infectious-04 \\
\hline Squamous cell carcinoma- 23 & Tuberculosis-04 \\
\hline Small cell carcinoma-10 & \\
Adenocarcinoma-09 & \\
Metastatic undifferentiated-01 & \\
\hline
\end{tabular}

\section{Table 3: Methods of sample collection}

\begin{tabular}{|clc|}
\hline S.N. & $\begin{array}{l}\text { Methods of sample } \\
\text { collection }\end{array}$ & $\begin{array}{c}\text { Positive results } \\
\text { (Number/Percentage) }\end{array}$ \\
\hline 1. & Histopathology alone & $17(39.53 \%)$ \\
\hline 2. & FNAC alone & $8(18.60 \%)$ \\
\hline 3. & BAL alone & $0(0)$ \\
\hline 4. & Bronchial Brush Alone & $4(9.30 \%)$ \\
\hline 5. & Trucut Biopsy & $1(2.32 \%)$ \\
\hline 6. & BAL + BB + HPE & $1(2.32 \%)$ \\
\hline 7. & BAL + BB & $4(9.30 \%)$ \\
\hline 8. & BB + HPE & $2(4.65 \%)$ \\
\hline 9. & FNAC + HPE & $1(2.32 \%)$ \\
\hline 10. & BAL + HPE & $5(11.62 \%)$ \\
\hline & Total & $\mathbf{4 3 ( 1 0 0 \% )}$ \\
\hline
\end{tabular}

FNAC- Fine Needle Aspiration Cytology, BAL-Bronchial Alveolar Lavage, BB-Bronchial Brush, HPE-Histopathology Evaluation

Table 4: Clinical presentation of the patients

\begin{tabular}{lc|}
\hline Symptoms & Number (\%) \\
\hline Cough & $17(39.5 \%)$ \\
\hline Hemoptysis & $14(32.5 \%)$ \\
\hline Weight loss & $4(9.3 \%)$ \\
\hline Shortness of breath & $4(9.3 \%)$ \\
\hline
\end{tabular}

Table 1: Radiological and bronchoscopy findings in the study

\begin{tabular}{lclc}
\hline Radiological findings & Number /Percentage $(\mathbf{n = 9 0 )}$ & Bronchoscopy findings & Number/Percentage (n=84) \\
\hline Mass & $57(63.3 \%)$ & Endobronchial growth & $34(40.47 \%)$ \\
Nodular & $8(8.9 \%)$ & Endobronchial narrowing & $16(19.04 \%)$ \\
Consolidation & $7(7.8 \%)$ & Inflammation & $7(8.33 \%)$ \\
Fibrosis & $7(7.8 \%)$ & Extraluminal compression & $6(7.14 \%)$ \\
Collapse & $6(6.7 \%)$ & Normal & $6(7.14 \%)$ \\
Pleural effusion & $3(3.3 \%)$ & Endobronchial obstruction & $5(5.95 \%)$ \\
Cavity & $2(2.2 \%)$ & Endobronchial secretion & $4(4.76 \%)$ \\
& & Haemorrhage & $4(4.76 \%)$ \\
\hline
\end{tabular}




\section{DISCUSSION}

In this study the overall bronchoscopic yield for positive histopathological examination (HPE) was $48.3 \%$. This value was low as comparedto diagnostic yield of conventional bronchoscopy5.

The major histological subtypes evaluated by the study were: squamous cell carcinoma $(53.48 \%)$, small lung cell carcinoma (23.25\%) and adenocarcinoma (20.93\%). These findings are quite contrast because internationally adenocarcinoma is still the leading subtype of lung malignancy ${ }^{6}$.

However, squamous cell carcinoma was still found to be the commonest histological subtype in various other study ${ }^{7}$. In a study done in Kashmir valley in India 2010, squamous cell carcinoma was the commonest histological type (67.5\%). Adenocarcinoma was found in only $3 \%$ of the cases. Similarly, study done by Jindal and Behera in Chandigarh in India, there were $34.3 \%$ of the squamous cell carcinoma patients and $25.9 \%$ of small cell lung carcinoma patients ${ }^{8}$. Karachi Cancer Registry also had similar data in 2006. There were $61 \%$ cases of Squamous Cell Carcinoma. The percentage for small cell lung carcinoma and adenocarcinoma were $12.5 \%$ and $6.9 \%$ respectively 9 .

The commonest side for occurrence of lung lesion in the study was right side (62.2\%) followed by left side $37.8 \%$. Among lobe, right upper lobe was the commonest site $(31.1 \%)$ followed by left upper lobe $(25.6 \%)$. The tendency of lesion to be malignant tends to be significant at right upper lobe ( $p-0.02)$. Turkish study published in Asia Journal of Cancer Prevention in 2011, also had right side as the commonest side for occurrence for lung malignancy. The upper lobe also was the commonest lobe in the study ${ }^{10}$.

\section{REFERENCES}

1. Forman D, Ferlay J. The global and regional burden of cancer. In: Stewart BW, Wild CP, editors. World Cancer Report 2014[Internet]. Lyon(FR): International Agency for Research on Cancer;2014 [cited 2017 Feb 18]. p. 17. [Full Text]

2. Cancer facts and figures 2018[Internet]. Atlanta: American Cancer Society; 2018[cited 2018 Feb 17]. [Full Text]

3. Ferlay J, Soerjomataram I, Ervik M, Dikshit R, Eser S, Mathers C et.al. GLOBOCAN 2012: Estimated Cancer Incidence, Mortality and Prevalence Worldwide in
Regarding the CECT chest findings, mass lesion was the commonest lesion (63.3\%), followed by nodular (8.9\%), consolidation (7.8\%) and fibrosis (7.8\%). However statistical chance for the yield of positive HPE was found only in mass lesion. Similarly, EBG had the highest yield for positive HPE with statistically significant association.

Wei-Juin Su et al. on chest x-ray guidelines in 1993 also had mass lesion in radiology that has significant association of occurrence of lung cancer. His study also showed, whenever there is endobronchial growth in bronchoscopy, the trend of lesion to be malignant is high"1.

Regarding the risk factor, this study failed to show any significant correlation of smoking history and occurrence of histological subtypes $(p-0.25)$. The reason may be that, there might have been other risk factors that might have triggered to develop malignancy besides smoking. Other risk factors such as genetic susceptibility, poor diet, occupational exposure and air pollution may act independently. So these factors should also have been taken to be accounted.

\section{CONCLUSION}

Conventional flexible bronchoscopy has always played pivotal role in diagnosis of any suspected lung lesion. Since lung malignancy has been one of the common forms of malignancy in our setup, early diagnosis and histological subtyping is vital for prognosis of these patient.

\section{ACKNOWLEDGEMENTS}

The authors are grateful to the Pathology Department, bronchoscopy team and supporting nursing staffs for their assistance with collecting data. Thanks are also due to the Ethical Committee team of Kathmandu Medical College Teaching Hospital.

2012 v 1.0. IARC Cancer Base No. 11 [Internet]. 2012 [cited 2017 Feb 17].[Full Text]

4. World Life Expectancy. Lung cancers in Nepal [Internet]. World Life Expectancy; 2014 Sep [cited 2018 Sep 9]. [Full Text]

5. Boonsarngsuk V, Raweelert P, Sukprapruet A, Chaiprasithikul R, Kiatboonsri S. Factors affecting the diagnostic yield of flexible bronchoscopy without guidance in pulmonary nodules or masses. Singapore Med J[Internet]. 2010 Aug [cited 2017 Feb 18];51(8):660-5. [PubMed]

6. Horn L, Pao W, Johnson DH. Neoplasms of lung. In: Longo DL, Fauci AS, Kasper DL, Hauser SL, Jameson 
$J \mathrm{~L}$, Loscalzo J, editors. Harrison's Principles of Internal Medicine. $18^{\text {the }}$. New York: Mcgraw-Hill; 2012. p.737-8

7. Koul PA, Kaul SK, Sheikh MM, Tasleem RA, Shah A. Lung cancer in the Kashmir valley. Lung India [Internet]. 2010 Jul-Sep [cited 2017 Mar 2];27(3):1317. [DOI]

8. Jindal SK, Behera D. Clinical spectrum of primary lung cancer-review of Chandigarh experience of 10 years. Lung India [Internet].1990 [cited 2017 March 8];8:94-8. [Full Text]

9. Bhurgri $Y$, Bhurgri A, Usman A, Sheukh N, Faridi N, Malik J, et al. Patho-epidemiology of lung cancer in Karachi (1995-2002). Asian Pac JCancerPrev[Internet].2006 Jan-Mar [cited 2016 Dec 18];7(1):60-4. [PubMed]

10. Sahin F, Yildiz P. Radiological, bronchoscopic and histopathological characteristics of patients with primary lung cancer in Turkey (2006-2009). Asian Pac J Cancer Prev[Internet].2011[cited 2017 Jun 8];12(8):1947-52. [PubMed]

11. Su WJ, Lee PY, Perng RP. Chest roentgenographic guidelines in the selection of patients for fiber opticbronchoscopy. Chest[Internet].1993 Apr [cited 2018 Jan 21];103(4):1198-201. [DOI] 